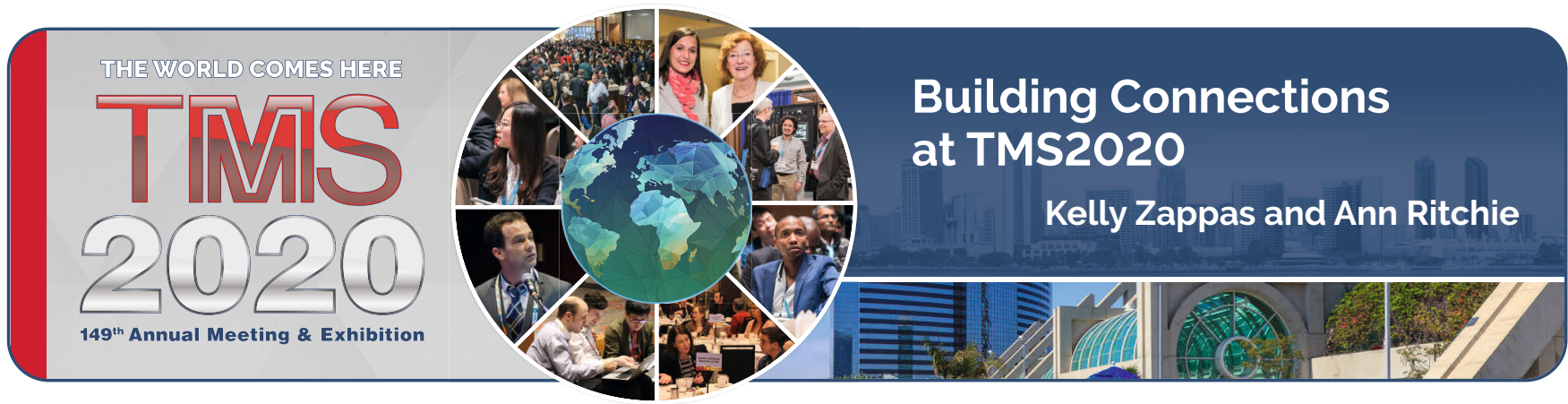

The TMS Annual Meeting \& Exhibition is often referred to as a family-like gathering for the global minerals, metals, and materials science and engineering community, bringing together members from around the world to share research, work together on topics of common interest, and build lasting relationships. The following pages offer a look at some of the social and networking events that brought people together during the TMS 2020 Annual Meeting \& Exhibition (TMS2020), February 23-27, in San Diego, California.

\section{Awards Ceremony and Banquet}

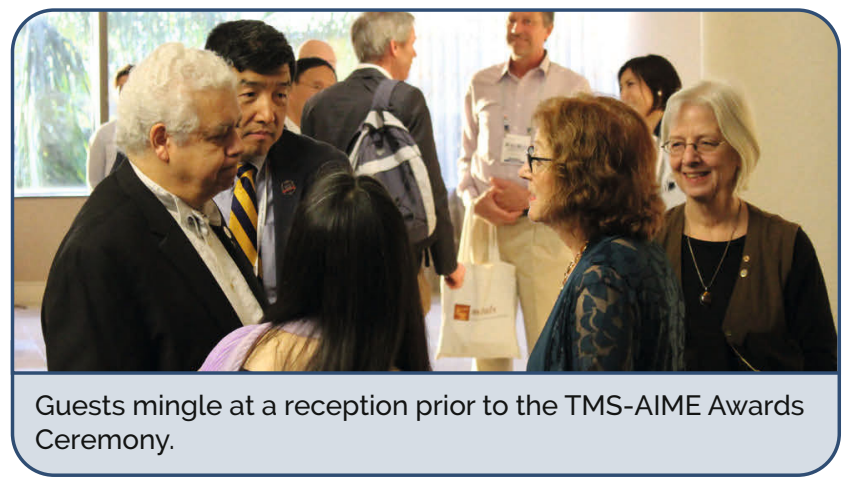

Nearly 50 individuals were recognized for significant achievements at all stages of their careers during the TMSAIME Honors \& Awards Ceremony and Banquet, held Wednesday, February 26. This event included presentation of awards by the American Institute of Mining,

Metallurgical, and Petroleum Engineers (AIME), of which TMS is a member society.

The highest honors of the evening went to the 2020 Class of TMS Fellows, recognizing the outstanding contributions of these individuals to the practice of metallurgy, materials science, and technology.

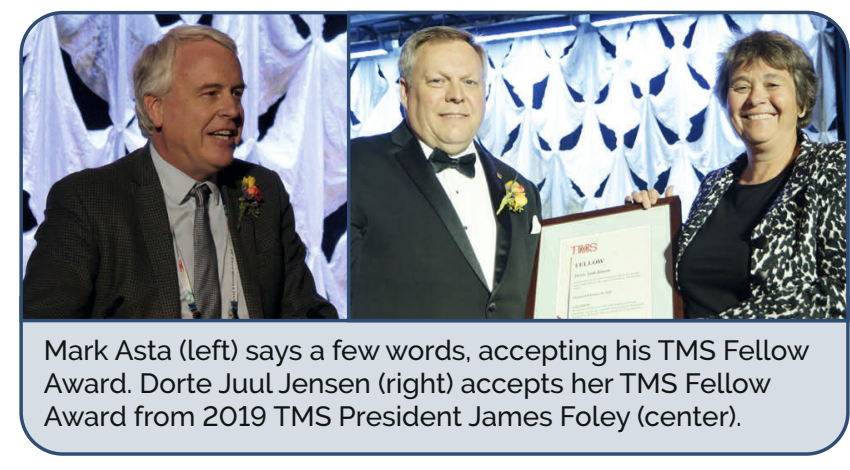

This year's Fellows included Mark Asta, who acknowledged TMS for playing such a central role, both in his career and in the development of integrated computational materials engineering (ICME); Rodney Boyer, who looked back at his career in titanium and recognized the mentors who helped him along the way; Marc DeGraef, who reflected on his 28 years of involvement with TMS, looking forward to the next 28; Diana Farkas, who talked about the lack of women in the field when she started and the importance of having role models like Julia Weertman and Millie Dresselhaus; Dorte Juul Jensen, who was enthusiastic about becoming a Fellow of the "best Society in the world," saying that nothing compares to TMS; Karl Kainer, a member of TMS's Magnesium Committee from its start, called TMS a professional family and the voice of the magnesium community; David McDowell, who said that, with TMS, he had the chance to work on ICME and the Materials Genome Initiative when they first took root; and Neville Moody, who said he's always found a home in TMS, where he's developed enduring friendships and collaborations.

"These Fellows' comments remind us of the richness of the TMS experience over the years," said presenter Elizabeth Holm, 2019 TMS Fellow, as she congratulated the new class of Fellows.

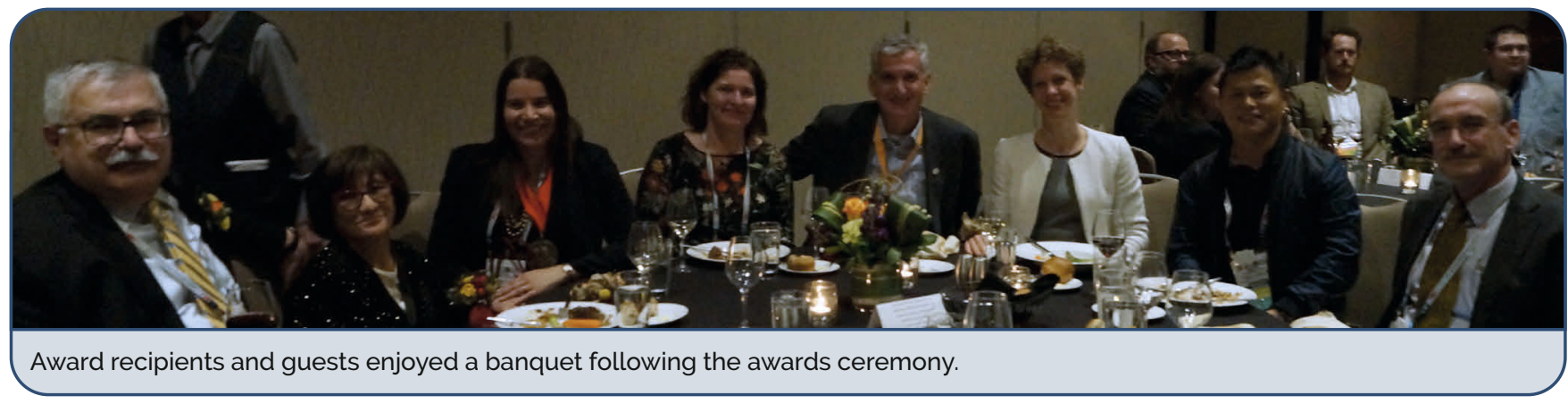




\section{Student Events}

The Colorado School of Mines "Orediggers" team successfully defended their title as champions at the 2020 TMS Materials Bowl on Sunday, February 23. They faced off against the University of Illinois "Speedy Spinels" in the final round of this day-long competition. This is the third consecutive win for the team and their eighth win overall.

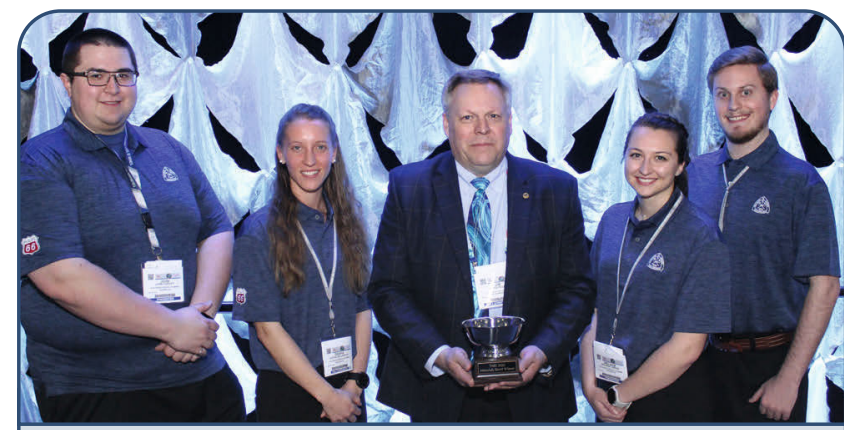

2019 TMS President James C. Foley (center) presented the trophy to the winning team members (from left to right): John Copley, Cierra Dellarova, Melissa Thrun, and Chad Haunschild.

The TMS Materials Bowl, held each year at the TMS Annual Meeting, is a materials-themed knowledge and trivia competition for university students. Twelve teams, made up of undergraduate and graduate students, competed in this year's event, which was sponsored by Goodfellow.

Later in the week, graduate and undergraduate students participated in the interactive Student Career Forum panel discussion, held on Tuesday, February 25, where they had the opportunity to learn from the career experiences of professionals working in industry, academia, and government. The experiences shared by the six panelists demonstrated that there is more than one way to build a career in materials science and engineering.

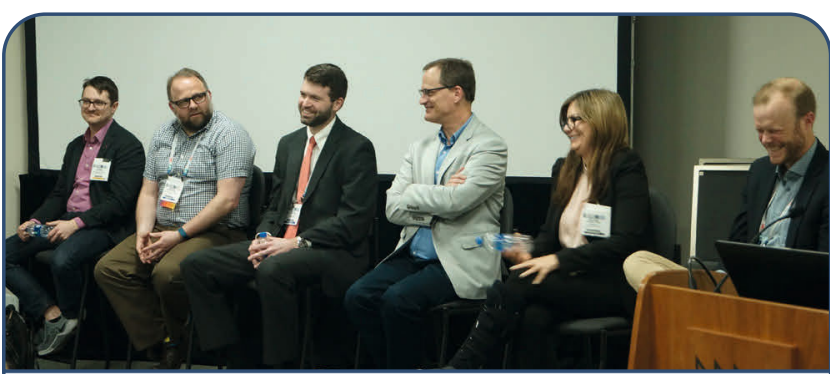

Student career forum participants, from left to right, were: Adam Hope, Thermo-Calc Software; Kester Clarke, Colorado School of Mines; Nolan Hoffman, U.S. Army Engineer Research and Development Center; Mark Horstemeyer, Liberty University; Melanie Lang, FormAlloy; and Remi Dingreville, Sandia National Laboratories.
Panelists fielded student questions, providing insight on when (and if) to go to graduate school, what it takes to create your own business, and how to recognize an opportunity when you see it, including opportunities that present themselves at a conference like TMS2020.

"Developing a network where everyone trusts you is important," said Kester Clarke, Colorado School of Mines. "Go and meet and talk to everyone this week. These meetings are really valuable for this."

A recording of this session is now available to view in the Recorded Presentations section of the TMS website at www.tms.org/Recordings. This event is organized each year by the TMS Young Professional Committee.

\section{Diversity and Inclusion Events}

TMS Pride of the TMS Diversity Committee kicked off the meeting week on Sunday, February 23, with its highly successful second annual LGBTQ+ and Allies Networking Mixer. Open to all TMS2020 attendees, the event provided an opportunity to share good food and conversation in a safe space as LGBTQ+ individuals and allies celebrated their common experiences and interests.

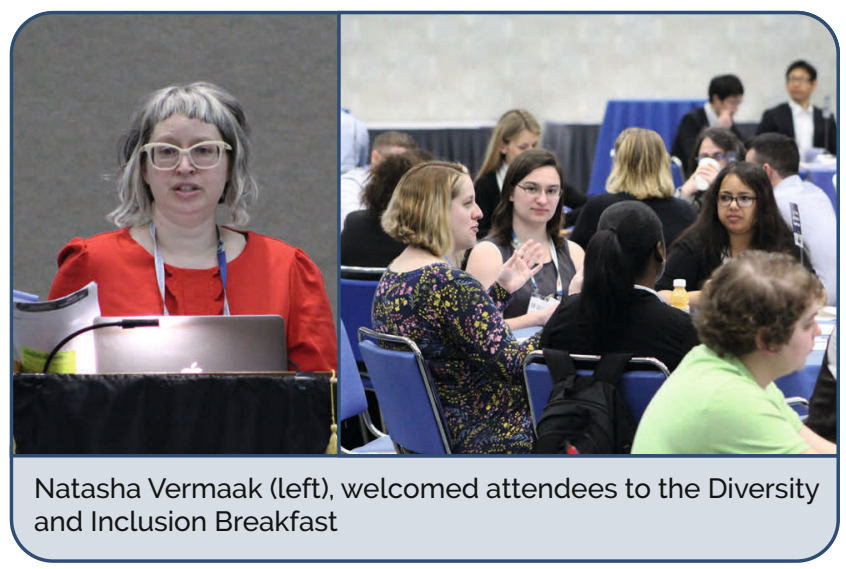

The TMS Leadership Development Initiative-a new program being developed by the Race and Ethnicity Working Group of the Diversity Committee-launched its pilot phase on Monday, February 24. The Initiative focuses on preparing and supporting TMS members from underrepresented ethnic minority groups in their pursuit of leadership roles and active engagement within TMS. Once the pilot phase has been concluded and evaluated, the program will be formally rolled out to TMS membership.

Concluding the week was the Fresh Coffee, Fresh Ideas: Diversity and Inclusion Breakfast, a well-established feature of the TMS Annual Meeting. Natasha Vermaak, chair of the Diversity Committee, welcomed attendees and then encouraged participants at each table to discuss an assigned topic, switching tables after 15 minutes to discuss a new topic related to diversity and inclusion issues. 


\section{Young Professional Tutorial Luncheon}

Early Career Faculty Fellows Jessica Krogstad, University of Illinois at Urbana-Champaign, and C. Cem Tasan, Massachusetts Institute of Technology, spoke at the Young Professionals Tutorial Luncheon and Lecture on Tuesday, February 25.

Krogstad presented "Challenging the Paradigm for Materials in Extreme Environments," where she discussed how the evolution of material properties in service is as important as initial properties. She encouraged materials scientists to further modernization of processing-property relationships by expecting change in the service of materials. "Deliberately dynamic materials would improve in extreme environments instead of degrading," Krogstad said.

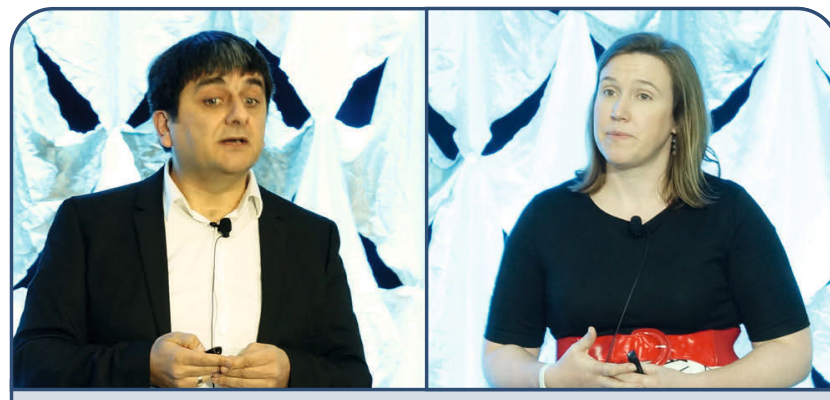

C. Cem Tasan (left) and Jessica Krogstad (right) speak at the Young Professionals Tutorial Luncheon and Lecture.

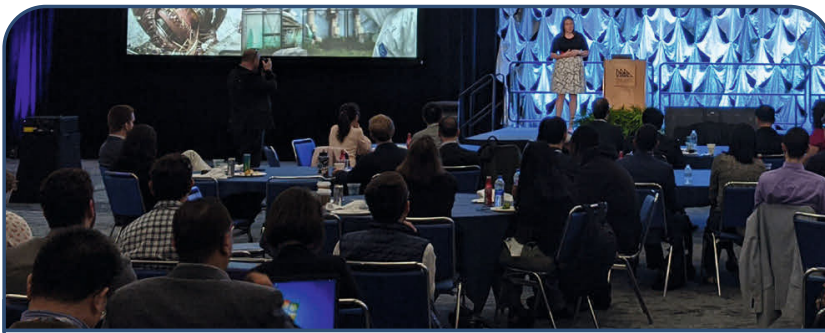

Guests attending the Young Professionals Tutorial Luncheon and Lecture.

Tasan spoke on refractory high-entropy alloys (rHEA) and asked, "What can mixing thermodynamics do for rHEA?" He returned to this question that lies at the core of the high-entropy alloy field to improve upon rHEA and explore how it results in good property combinations.

Both lecturers also gave career advice that underscored the importance of communication skills and networking, along with good work. Krogstad pushed her listeners to pursue great ideas, especially when they challenge the norm. "That's the advantage of being young and in the materials science field, right? Keep thinking big," she said. Tasan stressed the importance of diligence along the road to career success, but he also asked listeners to value occasional surprises and unexpected revelations. "Rely on a little randomness and make observations. Whatever path you are following, it takes a lot of work," he said.

\section{Networking Receptions}

Throughout the week, attendees had a number of opportunities to connect with old friends and meet new colleagues at social and networking events. Find more photos on Flickr at www.flickr.com/photos/ tmsevents/.

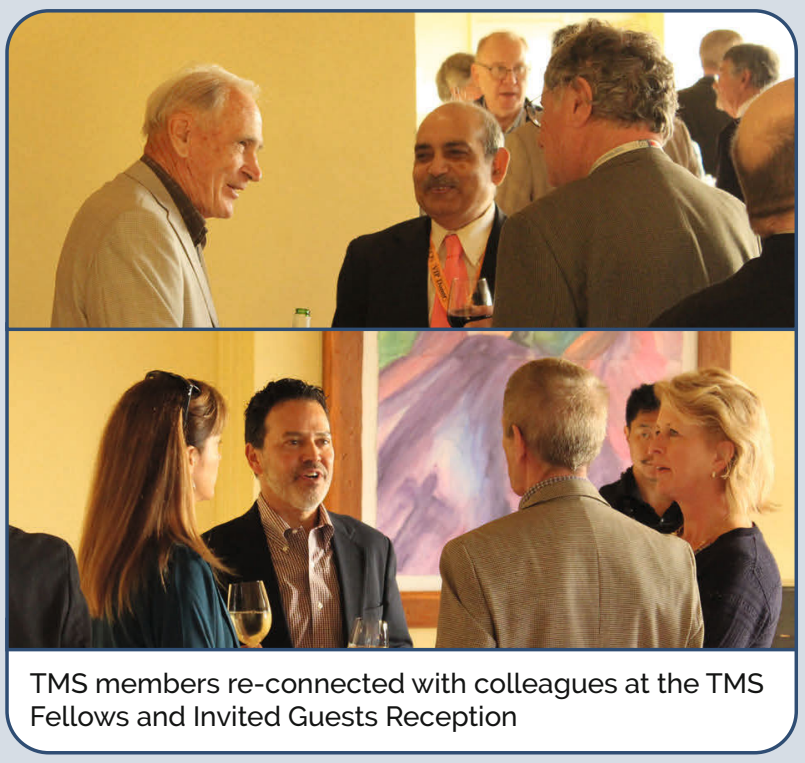

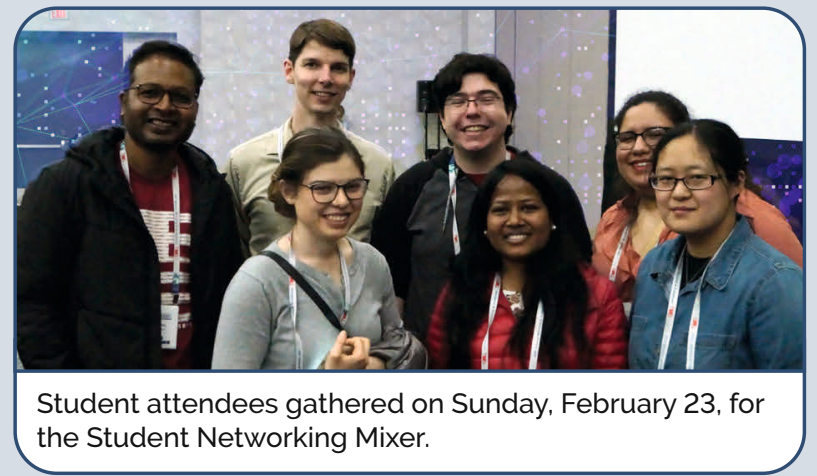

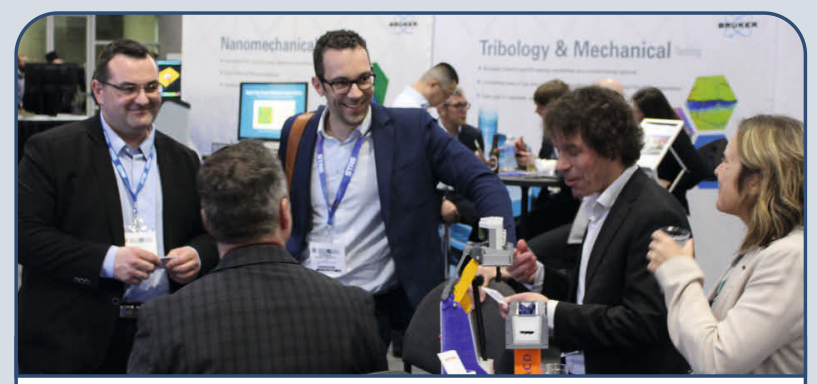

An opening reception, happy hour, poster sessions, and daily lunches brought attendees together in the TMS202O Exhibit Hall. 


\section{Division Luncheons}

The Structural Materials Division (SMD), Extraction \& Processing Division (EPD), Materials Processing \& Manufacturing Division (MPMD), and Light Metals Division (LMD) of TMS held luncheons featuring invited lectures and award presentations at TMS2020. The Functional Materials Division (FMD) award recipients were recognized at the FMD council meeting. Awards photos can be found on Flickr at www.flickr.com/photos/tmsevents.

\section{SMD Luncheon}

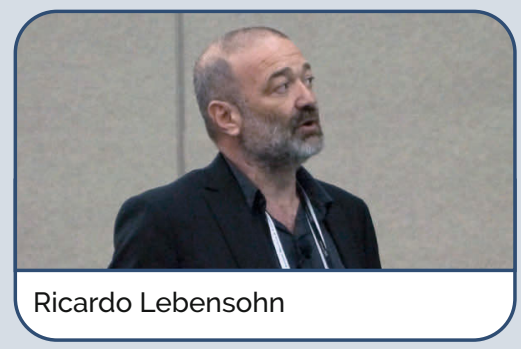

Ricardo Lebensohn, Los

Alamos National Laboratory, discussed "How Modelers Are Keeping up with Emerging Materials Characterization and Data Analytics Techniques" as the featured speaker at the SMD Luncheon on Monday, February 24.

Lebensohn looked at emerging methods in experimental mechanics and material characterization and at how we collect data. "All of this is enabled by increasing computing power," he said. "All of it is impacted by doing computations in a rapid fashion." We collect data and create models, he went on, but need to emphasize the connections between methods and models.

In some cases, he pointed out, we don't need machine learning; what we need is subject matter expertise. He closed his presentation by offering two examples of when machine learning is valuable and when subject matter expertise is more useful.

\section{EPD/MPMD/PbZn Luncheon}

Markus Reuter of the Helmholtz Institute Freiberg for Resource Technology addressed guests at the EPD/MPMD/PbZn 2020 Luncheon on Tuesday afternoon as the event's featured speaker. Reuter's talk, "Process Metallurgy as a Key Enabler of the Circular Economy: Digital Twinning of the Resource and Processing System," discussed the key role of metals in the circular economy.

While the general public often wants to do away with metals like lead or zinc completely, he said, taking any metal out of the system will make it collapse. Showing the image of a wheel, he explained, "If you take any section out, the wheel doesn't turn."

His talk included a discussion of how the public perceives the role of metals in society and how we can help promote a more accurate message about our field. "It's a beautiful field to be in," said Reuter.

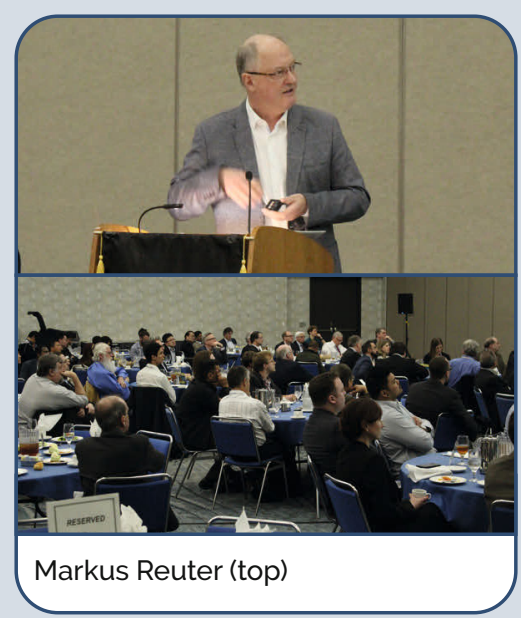

\section{LMD Luncheon}

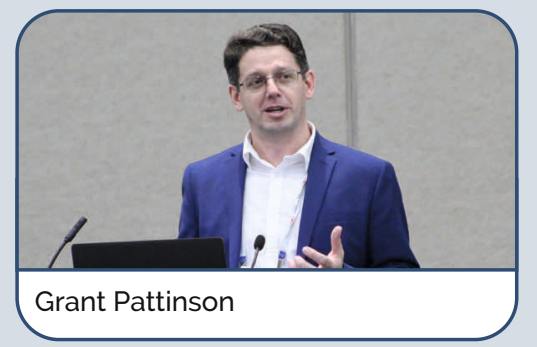

When you use a microscope, if you start by using the small knob, or fine focus, you likely won't get where you want to be. To get to the right place as quickly as possible, "use the big knob first," said Grant Pattinson in his presentation as the TMS Light Metals Division Luncheon lecturer on Wednesday, February 26.

Pattinson, who is manager of Tesla's Materials Engineering Metals and Ceramics team, shared examples of how this philosophy plays out in the development of materials and castings for Tesla.

"What sets us apart is, when we're doing design selection, we design specially produced materials," said Pattinson. "We don't necessarily use what is readily available."

Because they need to produce a large volume of parts per day for their products, timing is key. "Additive, for what we're doing, isn't fast enough," he said, before discussing the benefits and limits of high-pressure and lowpressure casting.

Samantha Schloder, recipient of the 2020 LMD Scholarship, also addressed luncheon attendees, sharing her experiences as a materials science/engineering student at the University of Pittsburgh and during a coop experience at Constellium in Ravenswood, West Virginia. 